\title{
BMJ Open Perinatal risk factors for premature ischaemic heart disease in a Swedish national cohort
}

\author{
Bengt Zöller, ${ }^{1}$ Jan Sundquist, ${ }^{1,2}$ Kristina Sundquist,, ${ }^{1,2}$ Casey Crump ${ }^{3}$
}

To cite: Zöller B,

Sundquist J, Sundquist K, et al. Perinatal risk factors for premature ischaemic heart disease in a Swedish national cohort. BMJ Open 2015;5: e007308. doi:10.1136/ bmjopen-2014-007308

- Prepublication history for this paper is available online. To view these files please visit the journal online (http://dx.doi.org/10.1136/ bmjopen-2014-007308).

Received 26 November 2014 Revised 22 April 2015 Accepted 26 April 2015

\section{CrossMark}

${ }^{1}$ Center for Primary Health Care Research, Lund University, Malmö, Sweden ${ }^{2}$ Stanford Prevention Research Center, Stanford University School of Medicine, Stanford, California, USA

${ }^{3}$ Department of Medicine, Stanford University School of Medicine, Stanford, California, USA

Correspondence to Dr Bengt Zöller; bengt.zoller@med.Iu.se

\section{ABSTRACT}

Objective: Several studies have reported associations between restricted fetal development, as shown by birth weight or birth length, and later ischaemic heart disease (IHD). However, few studies have examined the importance of these perinatal factors when taking into account gestational age at birth, hereditary factors, sociodemographic factors and comorbidities. This study investigated the importance of perinatal risk factors for premature IHD and myocardial infarction (MI) in a large Swedish cohort.

Setting and participants: National cohort study of 1970869 individuals who were live-born in Sweden in 1973 through 1992, and followed up to 2010 (ages 18-38 years).

\section{Primary and secondary outcome measures:}

The main outcome was IHD, and the secondary outcome was MI.

Results: A total of 668 individuals were diagnosed with IHD in 18.8 million person-years of follow-up. After adjusting for gestational age at birth, sociodemographic factors, comorbidities and family history of IHD, low fetal growth was associated with increased risk of IHD (HR for $<-2$ vs -1 to $<1 \mathrm{SD}$, $1.54 ; 95 \% \mathrm{Cl} 1.15$ to $2.07 ; \mathrm{p}=0.004$ ) and increased risk of $\mathrm{MI}$ (HR for $<-2$ vs -1 to $<1$ SD, $2.48 ; 95 \% \mathrm{Cl}$ 1.66 to $3.71 ; p<0.001$ ) in young adulthood. In contrast, gestational age at birth was not associated with the risk of IHD or MI.

Conclusions: In this large national cohort, low fetal growth was strongly associated with IHD and MI in young adulthood, independently of gestational age at birth, sociodemographic factors, comorbidities and family history of IHD.

\section{INTRODUCTION}

Low birth weight has been associated with increased risk of ischaemic heart disease (IHD) in adult life in a large number of studies. $^{1-18}$ A fetal origin hypothesis by Barker postulates that fetal undernutrition in middle to late gestation results in altered gene expression, which predisposes for IHD in adult life. ${ }^{19}$ However, few studies of birth weight in relation to IHD have examined the

\section{Strengths and limitations of this study}

- This birth cohort study is the largest nationwide study to examine the associations between restricted fetal development, as shown by birth weight, birth length or fetal growth and later ischaemic heart disease (IHD) or myocardial infarction (MI).

- Few studies have examined the importance of these perinatal factors when taking into account gestational age at birth, hereditary factors, sociodemographic factors and comorbidities.

- It highlights the importance of low fetal growth as a predictor for premature IHD and MI, independently of gestational age at birth, sociodemographic factors, comorbidities and family history of IHD.

- Study limitations include the unavailability of information on blood pressure, cholesterol, body mass index and smoking history. However, data were adjusted for parental socioeconomic factors that are related to life-style factors. Results were also adjusted for diagnosis of hypertension, diabetes, and cardiovascular and chromosomal anomalies.

- IHD and MI were identified from inpatient and outpatient diagnoses, thus we were unable to identify previously silent and undiagnosed events.

specific contributions of fetal growth and gestational age at birth. ${ }^{20-22}$ Kaijser et $a t^{21}$ studied 6425 Swedish individuals born between 1925 and 1949, and concluded that low gestational age adjusted for birth weight was not a risk factor, whereas low birth weight adjusted for gestational age was an independent risk factor for IHD. In a recent birth cohort from Sweden, between 1983 and 1995, low gestational age and low birth weight were associated with cerebrovascular disease but not with IHD. ${ }^{22}$ Moreover, in a population-based study of men born in 1913, no association between birth weight and IHD or cardiovascular disease mortality was observed. ${ }^{23}$ Thus, conflicting results exist regarding the contribution of birth weight and gestational age to the risk of IHD. 
Several mediators of the association between low birth weight and IHD have been suggested. Low birth weight has been associated with IHD risk factors such as obesity, hypertension and diabetes in adult life. ${ }^{24} 25$ Preterm birth also has been independently associated with diabetes and hypertension in adult life. ${ }^{26}{ }^{27}$ Studies among Swedish twins have shown an association between perinatal factors and myocardial infarction (MI) among dizygotic but not monozygotic twins, suggesting that genetic and early environmental factors that operate independently of birth weight may be important. ${ }^{28}$ Frankel et $a l^{3}$ found that childhood or adult socioeconomic factors and other adult risk factors did not explain the association between low birth weight and IHD. This is consistent with a systematic review that found that adjusting for childhood or adult socioeconomic factors did not alter the overall age-adjusted and sex-adjusted association between low birth weight and risk of IHD. ${ }^{20}$ However, few studies have taken into account hereditary factors, that is, family history of IHD, when examining the association between birth weight and IHD. ${ }^{22}$ Most studies have examined only IHD mortality and not IHD or MI morbidity. In addition, most previous studies have examined cohorts that were born before $1950 .^{1-18}$ Because perinatal care has improved over time, it is unclear to what extent earlier findings are generalisable to more recent birth cohorts.

We conducted a national cohort study in Sweden, to examine the association between perinatal factors and premature IHD and MI. A national cohort of infants born from 1973 through 1992 was followed up until 2010 for IHD and MI. We tested whether birth weight, birth length, standardised fetal growth or gestational age at birth is associated with an increased risk of IHD or MI independently of hereditary factors, sociodemographic factors and comorbidities.

\section{METHODS}

\section{Study population}

We identified 1984858 individuals in the Swedish Birth Registry who were live-born from 1973 through 1992 and still living in Sweden at age 18 years. We excluded 4625 $(0.2 \%)$ persons who had missing information for birth weight, and $6069(0.3 \%)$ others who had missing information for gestational age at birth. To remove possible coding errors, we excluded $3061(0.2 \%)$ who had a reported birth weight more than 4 SDs above or below the mean birth weight for gestational age and sex, based on a Swedish reference growth curve. ${ }^{29}$ To examine the risk of incident IHD and MI in young adulthood, we excluded 234 $(0.01 \%)$ others with a prior diagnosis of IHD before age 18 years. A total of 1970869 individuals (99.3\% of the original cohort) remained for inclusion in the study.

\section{IHD ascertainment}

The study cohort was followed up for the earliest incidence of IHD from age 18 years through 31 December
2010 (maximum attained age was 38 years). IHD was identified using primary and secondary diagnoses from the International Classification of Diseases (ICD), revisions 9 and 10 (codes 410-414 in ICD-9 and I20-I25 in ICD-10) in the Swedish Hospital Registry, Outpatient Registry and/or Cause of Death Registry. The Swedish Hospital Registry contains all primary and secondary hospital discharge diagnoses for six populous counties in southern Sweden, starting in 1964, and with nationwide coverage since 1987; and the Swedish Outpatient Registry contains all outpatient specialty clinic diagnoses nationwide starting in 2001. The Cause of Death Registry includes all deaths nationwide since 1964 for all persons registered in Sweden at the time of death. In secondary analyses, acute MI (MI; codes 410 in ICD-9 and I21 in ICD-10) was examined separately. The validity of IHD or MI diagnosis in the Hospital Registry has been reported to be $\sim 95 \% .^{30-32}$

\section{Perinatal, familial and comorbidity variables}

Perinatal and familial characteristics that may be associated with IHD were identified from the Swedish Birth Registry and national census data, which were linked using an anonymous personal identification number. ${ }^{33}{ }^{34}$ The following variables were examined as predictors of interest or adjustment variables: age (adjusted for as the Cox regression model time scale); sex (male or female); gestational age at birth (based primarily on maternal report of last menstrual period in the 1970 s, at which time ultrasound estimation was gradually introduced until it was used exclusively starting in the 1990s, modelled alternatively as a categorical $(<37$, $37-41,>42$ weeks) or continuous variable); fetal growth (a standardised variable defined as the number of SD from the mean birth weight for gestational age and sex based on a Swedish reference growth curve, ${ }^{29}$ modelled alternatively as a categorical $(<-2 ;-2$ to $<-1 ;-1$ to $<1$; $>1 \mathrm{SD}$ ) or continuous variable); birth weight (modelled alternatively as a categorical $(<2500, \quad 2500-3999$, $>4000 \mathrm{~g}$ ) or continuous variable); birth length (crownheel length in $\mathrm{cm}$, modelled alternatively as a categorical $(<48,48-52,>53 \mathrm{~cm})$ or continuous variable); multiple birth (singleton versus twin or higher order); birth order $(1,2,>3)$; maternal age at birth $(<20,20-24$, 25-29, 30-34, >35 years); maternal marital status (married/cohabiting, never married, divorced/ widowed); maternal and paternal education level (compulsory high school or less (<9 years), practical high school or some theoretical high school (10-11 years), theoretical high school and/or some college (1214 years), college and/or postgraduate study ( $>15$ years); examined separately for mothers and fathers); any inpatient or outpatient diagnosis of cardiovascular and chromosomal anomalies or syndromes (eg, including Marfan syndrome) (codes $746-747$ and 759 in ICD-8, 746-747, 758 and 759.8 in ICD-9, and Q20-Q28, Q87 and Q90-Q99 in ICD-10), diabetes mellitus (codes 250 in ICD-9 and E10-E14 in ICD-10), or hypertension 
(codes 401-405 in ICD-9 and I10-I15 in ICD-10); and parental history of IHD (yes or no; identified from the Swedish Hospital Registry in 1964-2010 and Outpatient Registry in 2001-2010 (codes 420 in ICD-7, 410-414 in ICD-8/9 and I20-I25 in ICD-10), not self-reported, thus enabling unbiased ascertainment during the study period). Chronic obstructive pulmonary disease (codes 491-492 in ICD-9 and J41-J44 in ICD-10) was also examined but, there were only five cases among persons with IHD, which were too few for further analysis as a predictor or adjustment variable.

\section{Statistical analysis}

Cox proportional hazards regression was used to estimate HRs and 95\% CIs for associations between perinatal or familial variables, and IHD. Individuals were censored at the time of death from any cause other than IHD $(\mathrm{n}=7158 ; 0.4 \%)$, or at the time of emigration as determined by the absence of a Swedish residential address in census data ( $\mathrm{n}=38440 ; 2.0 \%)$. Two different adjusted models were used: The first was adjusted for age (as the model time scale) and sex, and the second was further adjusted for other variables that were found to be associated with IHD (fetal growth, gestational age at birth, multiple birth, maternal marital status, maternal and paternal education, cardiovascular and chromosomal anomalies or syndromes, diabetes, hypertension and parental history of IHD). First-order interactions between sex and other variables were examined using likelihood ratio tests. The proportional hazards assumption was evaluated by graphical assessment of log-log plots and was met in each of the models. All statistical tests were two sided and used an $\alpha$-level of 0.05 . All analyses were conducted using Stata statistical software, V.12.1.

\section{RESULTS}

Among the 1970869 persons in this cohort, 668 $(0.03 \%)$ IHD cases were identified in 18.8 million person-years of follow-up ( 35.5 cases per million personyears). The median age at IHD diagnosis was 23.5 years (mean 27.5, SD 5.3). Males had a higher risk of IHD than females (fully adjusted HR, 1.75; 95\% CI 1.49 to 2.05; $\mathrm{p}<0.001$ ) (table 1). However, the associations between other variables and IHD did not vary by sex ( $p>0.05$ for each interaction, including for fetal growth $(\mathrm{p}=0.78)$, gestational age at birth $(\mathrm{p}=0.86)$ and birth weight $(p=0.65))$, hence non-stratified risk estimates are presented in table 1 .

\section{IHD results}

Fetal growth was inversely associated with the risk of IHD in young adulthood (table 1). Adjusting for age and sex, lowest fetal growth was associated with nearly twice the risk of IHD relative to normal fetal growth (HR for $<-2$ SD vs -1 to $<1$ SD, $1.89 ; 95 \%$ CI 1.42 to $2.51 ; \mathrm{p}<0.001)$. Further adjustment for gestational age at birth, sociodemographic factors, comorbidities and parental history of
IHD resulted in a moderately attenuated risk estimate that remained highly significant (fully adjusted HR for < $-2 \mathrm{SD}$ vs -1 to $<1 \mathrm{SD}, 1.54 ; 95 \%$ CI 1.15 to 2.07 ; $\mathrm{p}=0.004$ ), and an inverse trend remained across the full range of fetal growth (fully adjusted HR per additional 1 $\mathrm{SD}, 0.93$; $95 \%$ CI 0.87 to $0.99 ; \mathrm{p}=0.04$ ) (table 1 , adjusted model 2). A similar inverse association was also found between birth weight or birth length and IHD (table 1). In contrast, gestational age at birth was not associated with the risk of IHD in young adulthood (table 1).

Other strong independent risk factors for IHD in this cohort included hypertension, diabetes, cardiovascular and chromosomal anomalies or syndromes, parental history of IHD, multiple birth and low maternal or paternal education (table 1). Birth order, maternal age and maternal marital status were not significantly associated with IHD.

\section{MI results}

The findings for MI were overall similar to those for IHD but stronger in magnitude (table 2). Low fetal growth was strongly associated with increased risk of MI, and the risk estimates were only modestly affected by adjustment for gestational age at birth, sociodemographics, comorbidities and family history. In the fully adjusted model, lowest fetal growth was associated with more than twice the risk of MI relative to normal fetal growth (HR for $<-2 \mathrm{SD}$ vs -1 to $<1 \mathrm{SD}, 2.48$; $95 \%$ CI 1.66 to $3.71 ; \mathrm{p}<0.001)$, and a highly significant inverse trend was found across the full range of fetal growth (HR per additional $1 \mathrm{SD}, 0.78$; $95 \%$ CI 0.69 to 0.87 ; $\mathrm{p}<0.001$ ) (table 2, adjusted model 2). A similar, strong inverse association was also found between birth weight or birth length and MI (table 2). In contrast, gestational age at birth was not associated with the risk of MI in young adulthood (table 2).

A sensitivity analysis that excluded persons with any congenital anomalies $(\mathrm{n}=104473 ; 5.3 \%$, codes $740-759$ in ICD-8/9 and codes Q00-Q99 in ICD-10) produced very similar risk estimates as the main analysis, including those for fetal growth (IHD: fully adjusted HR per additional 1 SD, $0.92 ; 95 \%$ CI 0.85 to $0.99 ; \mathrm{p}=0.03$; MI: fully adjusted HR per additional $1 \mathrm{SD}, 0.80 ; 95 \%$ CI 0.70 to $0.91 ; \mathrm{p}=0.001$ ).

\section{DISCUSSION}

In this large national cohort study, we found that low fetal growth was associated with increased risk of IHD and MI in young adulthood, independently of gestational age at birth, sociodemographic factors, comorbidities and family history of IHD. Thus, low fetal growth adds to traditional risk factors for premature IHD and MI. ${ }^{35}$ These findings confirm that low fetal growth is the component of low birth weight accounting for its previously observed association with $\mathrm{IHD},{ }^{1-18}$ and further show that this association holds true in a more recent birth cohort from a developed country. Moreover, we 
Table 1 HRs for associations between perinatal or familial factors and ischaemic heart disease (IHD) in young adulthood (ages 18-38 years)

\begin{tabular}{|c|c|c|c|c|c|c|}
\hline & \multirow{2}{*}{$\begin{array}{l}\text { IHD } \\
(\mathrm{N}=668)\end{array}$} & \multirow{2}{*}{$\begin{array}{l}\text { No IHD } \\
(\mathrm{N}=1970 \text { 201) }\end{array}$} & \multicolumn{2}{|l|}{ Adjusted model $1^{*}$} & \multicolumn{2}{|l|}{ Adjusted model $2 \dagger$} \\
\hline & & & HR (95\% Cl) & p Value & HR (95\% Cl) & p Value \\
\hline \multicolumn{7}{|l|}{ Sex } \\
\hline Male & $435(65.1)$ & $1011914(51.4)$ & 1.76 (1.50 to 2.07$)$ & $<0.001$ & 1.75 (1.49 to 2.05$)$ & $<0.001$ \\
\hline Female & 233 (34.9) & 958287 (48.6) & 1.00 & & 1.00 & \\
\hline \multicolumn{7}{|l|}{ Fetal growth (SD) } \\
\hline$<-2$ & $54(8.1)$ & $73191(3.7)$ & $1.89(1.42$ to 2.51$)$ & $<0.001$ & 1.54 (1.15 to 2.07$)$ & 0.004 \\
\hline-2 to $<-1$ & $137(20.5)$ & 318840 (16.2) & 1.25 (1.03 to 1.52$)$ & 0.02 & $1.16(0.95$ to 1.41$)$ & 0.14 \\
\hline-1 to $<1$ & 400 (59.9) & $1302754(66.1)$ & 1.00 & & 1.00 & \\
\hline$>1$ & 77 (11.5) & $275416(14.0)$ & $0.96(0.76$ to 1.23$)$ & 0.77 & $0.98(0.77$ to 1.26$)$ & 0.90 \\
\hline $\begin{array}{l}\text { Per additional } 1 \text { SD } \\
\text { (trend test) }\end{array}$ & & & $0.88(0.82$ to 0.95$)$ & $<0.001$ & 0.93 (0.87 to 0.99$)$ & 0.04 \\
\hline \multicolumn{7}{|c|}{ Gestational age at birth (weeks) } \\
\hline$<37$ & $44(6.6)$ & $105352(5.3)$ & $1.36(1.00$ to 1.85$)$ & 0.05 & 1.07 (0.78 to 1.47$)$ & 0.68 \\
\hline $37-41$ & $545(81.6)$ & 1680326 (85.3) & 1.00 & & 1.00 & \\
\hline$>42$ & 79 (11.8) & $184523(9.4)$ & $1.03(0.82$ to 1.31$)$ & 0.79 & $0.97(0.77$ to 1.24$)$ & 0.83 \\
\hline $\begin{array}{l}\text { Per additional } 1 \text { week } \\
\text { (trend test) }\end{array}$ & & & 0.98 (0.94 to 1.02$)$ & 0.26 & $1.00(0.96$ to 1.05$)$ & 0.84 \\
\hline \multicolumn{7}{|l|}{ Birth weight $(g)$} \\
\hline$<2500$ & $40(6.0)$ & 76055 (3.9) & $1.70(1.23$ to 2.34$)$ & 0.001 & $1.32(0.90$ to 1.95$)$ & 0.16 \\
\hline 2500-3999 & $520(77.8)$ & 1557606 (79.1) & 1.00 & & 1.00 & \\
\hline$>4000$ & 108 (16.2) & 336540 (17.1) & $0.94(0.76$ to 1.15$)$ & 0.54 & 0.98 (0.80 to 1.21$)$ & 0.88 \\
\hline Per $1000 \mathrm{~g}$ (trend test) & & & $0.77(0.67$ to 0.88$)$ & $<0.001$ & $0.84(0.73$ to 0.96$)$ & 0.009 \\
\hline \multicolumn{7}{|l|}{ Birth length (cm) } \\
\hline$<48$ & $84(12.6)$ & $194563(9.9)$ & $1.44(1.14$ to 1.81$)$ & 0.002 & 1.17 (0.90 to 1.52$)$ & 0.24 \\
\hline $48-52$ & $492(73.7)$ & 1452416 (73.7) & 1.00 & & 1.00 & \\
\hline$>53$ & $91(13.6)$ & $311550(15.8)$ & $0.75(0.60$ to 0.94$)$ & 0.01 & 0.77 (0.62 to 0.97$)$ & 0.03 \\
\hline Unknown & $1(0.1)$ & $11672(0.6)$ & 0.48 (0.07 to 3.45$)$ & 0.47 & 0.41 (0.06 to 2.98$)$ & 0.38 \\
\hline Per cm (trend test) & & & 0.94 (0.91 to 0.97$)$ & $<0.001$ & 0.96 (0.93 to 1.00$)$ & 0.04 \\
\hline \multicolumn{7}{|l|}{ Multiple birth status } \\
\hline Singleton & 647 (96.9) & $1932944(98.1)$ & 1.00 & & 1.00 & \\
\hline Twin or higher order & $21(3.1)$ & 37257 (1.9) & $1.92(1.25$ to 2.97$)$ & 0.003 & 1.63 (1.04 to 2.57$)$ & 0.03 \\
\hline \multicolumn{7}{|l|}{ Birth order } \\
\hline 1 & 275 (41.2) & $824592(41.9)$ & 1.00 & & 1.00 & \\
\hline 2 & 250 (37.4) & 717996 (36.4) & $1.05(0.89$ to 1.25$)$ & 0.57 & 1.03 (0.87 to 1.23$)$ & 0.72 \\
\hline$>3$ & 143 (21.4) & 427613 (21.7) & $1.13(0.92$ to 1.38$)$ & 0.24 & 0.97 (0.78 to 1.21$)$ & 0.81 \\
\hline $\begin{array}{l}\text { Per } 1 \text { higher birth order } \\
\text { (trend test) }\end{array}$ & & & $1.06(0.96$ to 1.17$)$ & 0.24 & 0.99 (0.89 to 1.10$)$ & 0.88 \\
\hline \multicolumn{7}{|c|}{ Maternal age at delivery (years) } \\
\hline$<20$ & $41(6.1)$ & 60493 (3.1) & 1.46 (1.05 to 2.02$)$ & 0.03 & 1.21 (0.85 to 1.72$)$ & 0.28 \\
\hline $20-24$ & $184(27.5)$ & 463194 (23.5) & $1.03(0.86$ to 1.25$)$ & 0.72 & $0.96(0.79$ to 1.17$)$ & 0.67 \\
\hline $25-29$ & 258 (38.6) & 739852 (37.5) & 1.00 & & 1.00 & \\
\hline $30-34$ & 129 (19.3) & $491675(25.0)$ & 0.85 (0.69 to 1.05$)$ & 0.14 & 0.82 (0.67 to 1.02$)$ & 0.08 \\
\hline$>35$ & $56(8.4)$ & $214987(10.9)$ & $0.98(0.74$ to 1.31$)$ & 0.92 & 0.85 (0.64 to 1.14$)$ & 0.29 \\
\hline $\begin{array}{l}\text { Per each higher } \\
\text { category (trend test) }\end{array}$ & & & 0.92 (0.85 to 0.99$)$ & 0.03 & 0.93 (0.86 to 1.01$)$ & 0.08 \\
\hline \multicolumn{7}{|l|}{ Maternal marital status } \\
\hline Married/cohabiting & 416 (62.3) & $1460600(74.1)$ & 1.00 & & 1.00 & \\
\hline Never married & $170(25.4)$ & $297723(15.1)$ & $1.08(0.90$ to 1.29$)$ & 0.41 & $0.97(0.81$ to 1.17$)$ & 0.78 \\
\hline Divorced/widowed & 82 (12.3) & 211878 (10.8) & $1.33(1.05$ to 1.69$)$ & 0.02 & 1.25 (0.98 to 1.59$)$ & 0.07 \\
\hline \multicolumn{7}{|l|}{ Maternal education (years) } \\
\hline$<9$ & $226(33.8)$ & 468879 (23.8) & 1.00 & & 1.00 & \\
\hline $10-11$ & $254(38.0)$ & 759323 (38.5) & $0.89(0.75$ to 1.07$)$ & 0.22 & $0.96(0.80$ to 1.15$)$ & 0.67 \\
\hline $12-14$ & $92(13.8)$ & $445653(22.6)$ & 0.60 (0.47 to 0.77$)$ & $<0.001$ & $0.72(0.56$ to 0.93$)$ & 0.01 \\
\hline$>15$ & $48(7.2)$ & 214015 (10.9) & $0.55(0.41$ to 0.76$)$ & $<0.001$ & 0.75 (0.53 to 1.06$)$ & 0.10 \\
\hline Unknown & $48(7.2)$ & $82331(4.2)$ & 1.38 (1.01 to 1.88$)$ & 0.04 & $1.32(0.96$ to 1.82$)$ & 0.09 \\
\hline $\begin{array}{l}\text { Per each higher } \\
\text { category (trend test) }\end{array}$ & & & $0.80(0.74$ to 0.88$)$ & $<0.001$ & $0.88(0.80$ to 0.97$)$ & 0.01 \\
\hline
\end{tabular}


Table 1 Continued

\begin{tabular}{|c|c|c|c|c|c|c|}
\hline & \multirow{2}{*}{$\begin{array}{l}\text { IHD } \\
(\mathrm{N}=668)\end{array}$} & \multirow{2}{*}{$\begin{array}{l}\text { No IHD } \\
(\mathrm{N}=1970 \text { 201) } \\
\end{array}$} & \multicolumn{2}{|l|}{ Adjusted model $1^{*}$} & \multicolumn{2}{|l|}{ Adjusted model $2 \dagger$} \\
\hline & & & HR (95\% Cl) & $p$ Value & HR (95\% Cl) & p Value \\
\hline \multicolumn{7}{|c|}{ Paternal education (years) } \\
\hline$<9$ & $246(36.8)$ & $538836(27.3)$ & 1.00 & & 1.00 & \\
\hline $10-11$ & $203(30.4)$ & $631893(32.1)$ & $0.97(0.80$ to 1.17$)$ & 0.73 & $1.01(0.84$ to 1.22$)$ & 0.93 \\
\hline $12-14$ & $117(17.5)$ & $437434(22.2)$ & $0.68(0.55$ to 0.85$)$ & 0.001 & 0.79 (0.63 to 0.99$)$ & 0.05 \\
\hline$>15$ & $53(7.9)$ & $260395(13.2)$ & $0.52(0.39$ to 0.71$)$ & $<0.001$ & 0.69 (0.50 to 0.97$)$ & 0.03 \\
\hline Unknown & $49(7.3)$ & $101643(5.2)$ & $1.21(0.89$ to 1.65$)$ & 0.22 & $1.14(0.83$ to 1.57$)$ & 0.41 \\
\hline $\begin{array}{l}\text { Per each higher } \\
\text { category (trend test) }\end{array}$ & & & 0.82 (0.75 to 0.88$)$ & $<0.001$ & 0.90 (0.82 to 0.98$)$ & 0.02 \\
\hline \multicolumn{7}{|c|}{ Cardiovascular and chromosomal anomalies or syndromes } \\
\hline No & $613(91.8)$ & 1954894 (99.2) & 1.00 & & 1.00 & \\
\hline Yes & $55(8.2)$ & $15307(0.8)$ & 13.68 (10.38 to 18.03$)$ & $<0.001$ & $10.30(7.77$ to 13.66$)$ & $<0.001$ \\
\hline \multicolumn{7}{|l|}{ Diabetes } \\
\hline No & $606(90.7)$ & $1953382(99.1)$ & 1.00 & & 1.00 & \\
\hline Yes & $62(9.3)$ & $16819(0.9)$ & 10.49 (8.08 to 13.63$)$ & $<0.001$ & $5.56(4.15$ to 7.44$)$ & $<0.001$ \\
\hline \multicolumn{7}{|l|}{ Hypertension } \\
\hline No & $604(90.4)$ & 1964560 (99.7) & 1.00 & & 1.00 & \\
\hline Yes & $64(9.6)$ & $5641(0.3)$ & 23.37 (18.05 to 30.25 ) & $<0.001$ & 10.60 (7.91 to 14.20$)$ & $<0.001$ \\
\hline \multicolumn{7}{|l|}{ Parental history of IHD } \\
\hline No & 514 (76.9) & 1795779 (91.1) & 1.00 & & 1.00 & \\
\hline Yes & $154(23.1)$ & $174422(8.9)$ & 2.07 (1.73 to 2.48$)$ & $<0.001$ & 1.85 (1.54 to 2.22$)$ & $<0.001$ \\
\hline
\end{tabular}

${ }^{*}$ Adjusted for age and sex.

†Adjusted for age, sex, fetal growth, gestational age at birth, multiple birth, maternal marital status, maternal and paternal education, cardiovascular and chromosomal anomalies or syndromes, diabetes, hypertension and parental history of IHD.

Birth weight and birth length were each examined in separate models as alternatives to the standardised fetal growth variable. The reference category for all variables is indicated by an HR of 1.00. Missing data were excluded for trend tests.

found that the association between restricted fetal growth and premature MI was stronger than for IHD. In contrast, gestational age at birth was not associated with IHD or MI risk, consistent with previous Swedish birth cohort studies from 1925 to $1949 .^{21} 2236$ The present findings are in contrast with a recent study of venous thromboembolism (VTE) that found a weak association with low fetal growth but a stronger association with preterm birth. ${ }^{34}$ Thus, the perinatal factors predisposing for IHD/MI appear to be partially different from those predisposing to VTE in adult life. ${ }^{34}$ Although VTE and IHD/MI are frequently comorbid, the present study adds to other evidence showing differences in their risk factors. ${ }^{37}$

The associations we observed between low fetal growth and IHD/MI were only partly explained by socioeconomic factors, hereditary factors and common comorbidities. The remaining associations are likely related to other unmeasured long-term complications of restricted fetal growth, although the specific underlying mechanisms are not well-established. One hypothesis is that fetal undernutrition or malnutrition leads to altered gene expression, resulting in physiological alterations such as insulin resistance, vascular endothelial dysfunction and abnormal neuroendocrine stress responses. ${ }^{19}{ }^{38-40}$ Unknown genetic factors may also be important. ${ }^{28}$ There is a negative correlation between maternal blood pressure during pregnancy and birth weight. ${ }^{41}$ Other possible confounding factors include maternal smoking ${ }^{42}$ and malformation syndromes ${ }^{43}$ which may contribute to both small size at birth, and a possible increased risk of IHD and MI. Our findings were adjusted for cardiovascular and chromosomal anomalies, but information about maternal smoking was lacking. Though we adjusted for parental socioeconomic factors as a proxy for life-style factors such as smoking, the influence of parental smoking on the relationship between fetal growth and adult IHD or MI warrants further investigation.

The most important strength of the current study was its ability to examine the association between perinatal risk factors and risk of IHD/MI in young adulthood using nationwide birth, hospital, outpatient and death registry data for a large national cohort. The results were adjusted for other perinatal risk factors as well as other broadly measured potential confounders. Information on common comorbidities enabled us to examine their influence on the main findings.

Study limitations include the unavailability of information on blood pressure, cholesterol, body mass index and smoking history. However, the results were adjusted for parental socioeconomic factors, which are related to life-style factors such as smoking, and for diagnoses of hypertension, diabetes, and cardiovascular and chromosomal anomalies. IHD and MI were identified from inpatient and outpatient specialty clinic diagnoses, thus we were unable to identify previously silent and undiagnosed events. Information on genetic risk factors was unavailable, although the results were adjusted for 
Table 2 HRs for associations between perinatal or familial factors and acute MI in young adulthood (ages 18-38 years)

\begin{tabular}{|c|c|c|c|c|c|c|}
\hline & \multirow{2}{*}{$\begin{array}{l}\mathrm{MI} \\
(\mathrm{N}=239)\end{array}$} & \multirow{2}{*}{$\begin{array}{l}\text { No MI } \\
(\mathrm{N}=1970630)\end{array}$} & \multicolumn{2}{|l|}{ Adjusted model $1^{*}$} & \multicolumn{2}{|l|}{ Adjusted model $2 \dagger$} \\
\hline & & & HR (95\% Cl) & p Value & $\mathrm{HR}(95 \% \mathrm{Cl})$ & p Value \\
\hline \multicolumn{7}{|l|}{ Sex } \\
\hline Male & $170(71.1)$ & 1012179 (51.4) & 2.32 (1.76 to 3.07$)$ & $<0.001$ & 2.33 (1.76 to 3.08$)$ & $<0.001$ \\
\hline Female & 69 (28.9) & 958451 (48.6) & 1.00 & & 1.00 & \\
\hline \multicolumn{7}{|l|}{ Fetal growth (SD) } \\
\hline$<-2$ & $32(13.4)$ & $73213(3.7)$ & 2.36 (1.78 to 3.12$)$ & $<0.001$ & 2.48 (1.66 to 3.71$)$ & $<0.001$ \\
\hline-2 to $<-1$ & $53(22.2)$ & 318924 (16.2) & 1.45 (1.05 to 1.99$)$ & 0.02 & $1.31(0.95$ to 1.80$)$ & 0.10 \\
\hline-1 to $<1$ & $132(55.2)$ & $1303022(66.1)$ & 1.00 & & 1.00 & \\
\hline$>1$ & $22(9.2)$ & 275471 (14.0) & 0.84 (0.53 to 1.32 ) & 0.45 & 0.86 (0.54 to 1.34$)$ & 0.50 \\
\hline $\begin{array}{l}\text { Per additional } 1 \text { SD } \\
\text { (trend test) }\end{array}$ & & & 0.71 (0.63 to 0.80 ) & $<0.001$ & 0.78 (0.69 to 0.87 ) & $<0.001$ \\
\hline \multicolumn{7}{|c|}{ Gestational age at birth weeks) } \\
\hline$<37$ & $16(6.7)$ & $105380(5.3)$ & 1.44 (0.86 to 2.39 ) & 0.17 & 1.05 (0.62 to 1.78$)$ & 0.85 \\
\hline $37-41$ & 188 (78.7) & 1680683 (85.3) & 1.00 & & 1.00 & \\
\hline$>42$ & $35(14.6)$ & 184567 (9.4) & 1.29 (0.90 to 1.84$)$ & 0.17 & 1.12 (0.77 to 1.62$)$ & 0.55 \\
\hline $\begin{array}{l}\text { Per additional } 1 \text { week } \\
\text { (trend test) }\end{array}$ & & & 1.00 (0.93 to 1.07$)$ & 0.94 & $1.02(0.96$ to 1.10$)$ & 0.49 \\
\hline \multicolumn{7}{|l|}{ Birth weight (g) } \\
\hline$<2500$ & $22(9.2)$ & 76073 (3.9) & 2.71 (1.74 to 4.22 ) & $<0.001$ & 2.26 (1.31 to 3.91$)$ & 0.004 \\
\hline 2500-3999 & $182(76.2)$ & 1557944 (79.1) & 1.00 & & 1.00 & \\
\hline$>4000$ & 35 (14.6) & $336613(17.1)$ & 0.85 (0.59 to 1.22 ) & 0.37 & 0.86 (0.59 to 1.24$)$ & 0.42 \\
\hline Per $1000 \mathrm{~g}$ (trend test) & & & 0.58 (0.46 to 0.71$)$ & $<0.001$ & 0.61 (0.47 to 0.79$)$ & $<0.001$ \\
\hline \multicolumn{7}{|l|}{ Birth length $(\mathrm{cm})$} \\
\hline$<48$ & $36(15.1)$ & 194611 (9.9) & 4 to 2.55$)$ & 0.002 & 1.43( & 0.09 \\
\hline $48-52$ & 176 (73.6) & 1452732 (73.7) & 1.00 & & 1.00 & \\
\hline$>53$ & 27 (11.3) & $311614(15.8)$ & 0.59 (0.39 to 0.89$)$ & 0.01 & 0.59 (0.39 to 0.89$)$ & 0.01 \\
\hline Unknown & $0(0.0)$ & $11673(0.6)$ & NE & NE & $\mathrm{NE}$ & NE \\
\hline Per $\mathrm{cm}$ (trend test) & & & 0.9 & $<0.001$ & $0.93(0.88$ & 0.006 \\
\hline \multicolumn{7}{|l|}{ Multiple birth status } \\
\hline Singleton & $228(95.4)$ & 1933363 (98.1) & 1.00 & & 1.00 & \\
\hline Twin or higher & $11(4.6)$ & 37267 (1.9) & 2.91 (1.59 to 5.34 ) & 0.001 & 2.25 (1.19 to 4.25$)$ & 0.01 \\
\hline \multicolumn{7}{|l|}{ Birth order } \\
\hline 1 & $104(43.5)$ & 824763 (41.9) & 1.00 & & 1.00 & \\
\hline 2 & $81(33.9)$ & 718165 (36.4) & 0.90 (0.68 to 1.21$)$ & 0.49 & 0.90 (0.67 to 1.22$)$ & 0.50 \\
\hline$>3$ & 54 (22.6) & $427702(21.7)$ & to 1.60$)$ & 0.40 & 0.95 (0.66 to 1.35$)$ & 0.76 \\
\hline $\begin{array}{l}\text { Per } 1 \text { higher birth order } \\
\text { (trend test) }\end{array}$ & & & 1.05 (0.89 to 1.24$)$ & 0.56 & 0.96 (0.81 to 1.15$)$ & 0.69 \\
\hline \multicolumn{7}{|c|}{ Maternal age at delivery (years) } \\
\hline$<20$ & $15(6.3)$ & 605 & 1.53 (0.89 to 2.66$)$ & 0.13 & to 2.13 ) & 0.57 \\
\hline $20-24$ & $79(33.1)$ & 463299 (23.5) & 1.31 (0.97 to 1.78 ) & 0.08 & 1.17 (0.85 to 1.61$)$ & 0.33 \\
\hline $25-29$ & $86(36.0)$ & 740024 (37.6) & 1.00 & & 1.00 & \\
\hline 30-34 & $41(17.1)$ & $491763(25.0)$ & 0.83 (0.57 to 1.21$)$ & 0.33 & 0.80 (0.55 to 1.17$)$ & 0.25 \\
\hline$>35$ & $18(7.5)$ & $215025(10.9)$ & 1.00 (0.60 to 1.67$)$ & 0.99 & $0.83(0.50$ to 1.39$)$ & 0.49 \\
\hline $\begin{array}{l}\text { Per each higher category } \\
\text { (trend test) }\end{array}$ & & & 0.85 (0.75 to 0.97$)$ & 0.01 & 0.88 (0.76 to 1.00$)$ & 0.06 \\
\hline \multicolumn{7}{|l|}{ Maternal marital status } \\
\hline Married/cohabiting & $147(61.5)$ & 1460869 (74.1) & 1.00 & & 1.00 & \\
\hline Never married & $67(28.0)$ & $297826(15.1)$ & $1.12(($ & 0.43 & $0.95(C$ & 0.72 \\
\hline Divorced/widowed & $25(10.5)$ & 211935 (10.8) & 1.18 (0.77 to 1.81$)$ & 0.44 & 1.06 (0.69 to 1.63$)$ & 0.79 \\
\hline \multicolumn{7}{|l|}{ Maternal education (years) } \\
\hline$<9$ & 89 (37.2) & 469016 (23.8) & 1.00 & & 1.00 & \\
\hline $10-11$ & $91(38.1)$ & 759486 (38.5) & 0.84 (0.63 to 1.13 ) & 0.25 & 0.94 (0.70 to 1.26$)$ & 0.68 \\
\hline $12-14$ & 30 (12.6) & 445715 (22.6) & 0.52 (0.34 to 0.79$)$ & 0.002 & $0.68(0.44$ to 1.05$)$ & 0.08 \\
\hline$>15$ & $10(4.2)$ & 214053 (10.9) & 0.30 (0.16 to 0.58$)$ & $<0.001$ & 0.48 (0.23 to 0.97$)$ & 0.04 \\
\hline Unknown & $19(7.9)$ & 82360 (4.2) & 1.45 (0.88 to 2.38 ) & 0.15 & 1.34 (0.81 to 2.24$)$ & 0.26 \\
\hline $\begin{array}{l}\text { Per each higher category } \\
\text { (trend test) }\end{array}$ & & & 0.71 (0.61 to 0.82 ) & $<0.001$ & 0.81 (0.69 to 0.96$)$ & 0.02 \\
\hline
\end{tabular}


Table 2 Continued

\begin{tabular}{|c|c|c|c|c|c|c|}
\hline & \multirow{2}{*}{$\begin{array}{l}\text { MI } \\
(\mathrm{N}=239)\end{array}$} & \multirow{2}{*}{$\begin{array}{l}\text { No MI } \\
(\mathrm{N}=1970630)\end{array}$} & \multicolumn{2}{|l|}{ Adjusted model 1* } & \multicolumn{2}{|l|}{ Adjusted model $2 \dagger$} \\
\hline & & & HR (95\% Cl) & p Value & HR (95\% Cl) & p Value \\
\hline \multicolumn{7}{|l|}{ Paternal education (years) } \\
\hline$<9$ & 99 (41.4) & $538983(27.4)$ & 1.00 & & 1.00 & \\
\hline $10-11$ & $70(29.3)$ & $632026(32.1)$ & 0.86 (0.64 to 1.17$)$ & 0.35 & $0.92(0.67$ to 1.25$)$ & 0.58 \\
\hline $12-14$ & $37(15.5)$ & 437514 (22.2) & 0.55 (0.37 to 0.80$)$ & 0.002 & 0.68 (0.46 to 1.00$)$ & 0.05 \\
\hline$>15$ & $13(5.4)$ & 260435 (13.2) & $0.33(0.18$ to 0.59$)$ & $<0.001$ & 0.54 (0.29 to 1.02$)$ & 0.06 \\
\hline Unknown & $20(8.4)$ & $101672(5.2)$ & 1.28 (0.79 to 2.07$)$ & 0.32 & $1.214(0.74$ to 1.99$)$ & 0.45 \\
\hline $\begin{array}{l}\text { Per each higher category } \\
\text { (trend test) }\end{array}$ & & & $0.72(0.63$ to 0.83$)$ & $<0.001$ & $0.83(0.71$ to 0.97$)$ & 0.02 \\
\hline \multicolumn{7}{|c|}{ Cardiovascular and chromosomal anomalies or syndromes } \\
\hline No & $221(92.5)$ & $1955286(99.2)$ & 1.00 & & 1.00 & \\
\hline Yes & $18(7.5)$ & $15344(0.8)$ & 12.75 (7.89 to 20.62$)$ & $<0.001$ & $9.14(5.60$ to 14.90$)$ & $<0.001$ \\
\hline \multicolumn{7}{|l|}{ Diabetes } \\
\hline No & $205(85.8)$ & $1953783(99.1)$ & 1.00 & & 1.00 & \\
\hline Yes & $34(14.2)$ & $16847(0.9)$ & 16.55 (11.51 to 23.79$)$ & $<0.001$ & $9.60(6.35$ to 14.50$)$ & $<0.001$ \\
\hline \multicolumn{7}{|c|}{ 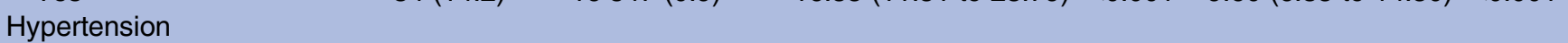 } \\
\hline No & $215(90.0)$ & $1964949(99.7)$ & 1.00 & & 1.00 & \\
\hline Yes & $24(10.0)$ & $5681(0.3)$ & 23.13 (15.16 to 35.30$)$ & $<0.001$ & 7.55 (4.66 to 12.24$)$ & $<0.001$ \\
\hline \multicolumn{7}{|l|}{ Parental history of IHD } \\
\hline No & $169(70.7)$ & $1796124(91.1)$ & 1.00 & & 1.00 & \\
\hline Yes & $70(29.3)$ & 174506 (8.9) & 2.73 (2.06 to 3.61$)$ & $<0.001$ & 2.36 (1.78 to 3.13$)$ & $<0.001$ \\
\hline
\end{tabular}

family history of IHD. It is also unclear to what extent our findings will apply to later birth cohorts or older ages. However, generalisability to other populations seems likely, given the overall consistency of results across different birth cohorts. ${ }^{1-18}$

In summary, among individuals born in Sweden between 1973 and 1992, low fetal growth was a strong independent risk factor for IHD and MI in young adulthood. In contrast, gestational age at birth was not associated with the risk of IHD or MI. These findings call for better awareness of the long-term risk of IHD/MI among growth-restricted infants.

Acknowledgements The registers used in the present study are maintained by Statistics Sweden and the National Board of Health and Welfare.

Contributors BZ was involved in the conception and design, analysis and interpretation of data, drafted the initial manuscript and approved the final manuscript. JS was involved in the conception and design, acquisition, analysis and interpretation of data, revised the manuscript and approved the final manuscript. KS was involved in the conception and design, and acquisition, analysis and interpretation of data, revised the manuscript and approved the final manuscript as submitted. CC was involved in the conception and design, analysis and interpretation of data, revised the manuscript and approved the final manuscript. All authors approved the final manuscript as submitted and agree to be accountable for all aspects of the work.

Funding This work was supported by grants awarded to BZ by the Swedish Heart-Lung Foundation; ALF funding awarded to BZ, KS and JS by Region Skåne; grants awarded to BZ, KS and JS by the Swedish Research Council; and grants awarded to JS by King Gustaf V and Queen Victoria's Foundation of Freemasons. Research reported in this publication was also supported by the National Heart, Lung, And Blood Institute of the National Institutes of
Health under Award Number R01HL116381 to KS. The content is solely the responsibility of the authors.

Competing interests None declared.

Ethics approval The study was approved by the Ethics Committee at Lund University and complied with recommendations of the Declaration of Helsinki.

Provenance and peer review Not commissioned; externally peer reviewed.

Data sharing statement No additional data are available.

Open Access This is an Open Access article distributed in accordance with the terms of the Creative Commons Attribution (CC BY 4.0) license, which permits others to distribute, remix, adapt and build upon this work, for commercial use, provided the original work is properly cited. See: http:// creativecommons.org/licenses/by/4.0/

\section{REFERENCES}

1. Barker DJ, Winter PD, Osmond C, et al. Weight in infancy and death from ischaemic heart disease. Lancet 1989;2:577-80.

2. Frankel S, Elwood $P$, Sweetnam $P$, et al. Birthweight, adult risk factors and incident coronary heart disease: the Caerphilly Study. Public Health 1996;110:139-43.

3. Frankel S, Elwood P, Sweetnam P, et al. Birthweight, body-mass index in middle age, and incident coronary heart disease. Lancet 1996;348:1478-80.

4. Stein $\mathrm{CE}$, Fall $\mathrm{CH}$, Kumaran $\mathrm{K}$, et al. Fetal growth and coronary heart disease in south India. Lancet 1996;348:1269-73.

5. Rich-Edwards JW, Stampfer MJ, Manson JE, et al. Birth weight and risk of cardiovascular disease in a cohort of women followed up since 1976. BMJ 1997:315:396-400.

6. Martyn CN, Barker DJ, Osmond C. Mothers' pelvic size, fetal growth, and death from stroke and coronary heart disease in men in the UK. Lancet 1996;348:1264-8.

7. Leon DA, Lithell HO, Vagero D, et al. Reduced fetal growth rate and increased risk of death from ischaemic heart disease: cohort study of 15000 Swedish men and women born 1915-29. BMJ 1998;317:241-5. 
8. Eriksson JG, Forsen T, Tuomilehto J, et al. Catch-up growth in childhood and death from coronary heart disease: longitudinal study. BMJ 1999;318:427-31.

9. Barker DJ, Eriksson JG, Forsen T, et al. Fetal origins of adult disease: strength of effects and biological basis. Int $\mathrm{J}$ Epidemiol 2002;31:1235-9.

10. Lawlor DA, Davey Smith G, Ebrahim S. Birth weight is inversely associated with coronary heart disease in post-menopausal women: findings from the British Women's Heart and Health Study. $J$ Epidemiol Community Health 2004:58:120-5.

11. Syddall HE, Sayer AA, Simmonds SJ, et al. Birth weight, infant weight gain, and cause-specific mortality: the Hertfordshire Cohort Study. Am J Epidemiol 2005;161:1074-80.

12. Rich-Edwards JW, Kleinman K, Michels KB, et al. Longitudinal study of birth weight and adult body mass index in predicting risk of coronary heart disease and stroke in women. BMJ 2005;330:1115.

13. Lawlor DA, Ronalds $\mathrm{G}$, Clark $\mathrm{H}$, et al. Birth weight is inversely associated with incident coronary heart disease and stroke among individuals born in the 1950s: findings from the Aberdeen Children of the 1950s prospective cohort study. Circulation 2005;112:1414-18.

14. Kajantie E, Osmond C, Barker DJ, et al. Size at birth as a predictor of mortality in adulthood: a follow-up of 350000 person-years. Int $J$ Epidemiol 2005;34:655-63.

15. Tanis BC, Kapiteijn K, Hage RM, et al. Dutch women with a low birth weight have an increased risk of myocardial infarction later in life: a case control study. Reprod Health 2005;2:1.

16. Osler M, Lund R, Kriegbaum M, et al. The influence of birth weight and body mass in early adulthood on early coronary heart disease risk among Danish men born in 1953. Eur J Epidemiol 2009;24:57-61.

17. Rajaleid K, Janszky I, Hallqvist J. Small birth size, adult overweight, and risk of acute myocardial infraction. Epidemiology 2011;22:138-47.

18. Fan Z, Zhang ZX, Li Y, et al. Relationship between birth size and coronary heart disease in China. Ann Med 2010;42:596-602.

19. Barker DJ. Fetal origins of coronary heart disease. BMJ 1995;311:171-4.

20. Huxley $\mathrm{R}$, Owen $\mathrm{CG}$, Whincup $\mathrm{PH}$, et al. Is birth weight a risk factor for ischemic heart disease in later life? Am J Clin Nutr 2007;85:1244-50.

21. Kaijser M, Bonamy AK, Akre O, et al. Perinatal risk factors for ischemic heart disease: disentangling the roles of birth weight and preterm birth. Circulation 2008:117:405-10.

22. Ueda $\mathrm{P}, \mathrm{Cnattingius} \mathrm{S}$, Stephansson $\mathrm{O}$, et al. Cerebrovascular and ischemic heart disease in young adults born preterm: a populationbased Swedish cohort study. Eur J Epidemiol 2014;29:253-60.

23. Eriksson M, Wallander MA, Krakau I, et al. The impact of birth weight on coronary heart disease morbidity and mortality in a birth cohort followed up for 85 years: a population-based study of men born in 1913. J Intern Med 2004;256:472-81.

24. Curhan GC, Chertow GM, Willett WC, et al. Birth weight and adult hypertension and obesity in women. Circulation 1996;94:1310-15.

25. Curhan GC, Willett WC, Rimm EB, et al. Birth weight and adult hypertension, diabetes mellitus, and obesity in US men. Circulation 1996;94:3246-50.
26. Crump C, Winkleby MA, Sundquist K, et al. Risk of diabetes among young adults born preterm in Sweden. Diabetes Care 2011;34:1109-13.

27. Crump C, Winkleby MA, Sundquist K, et al. Risk of hypertension among young adults who were born preterm: a Swedish national study of 636,000 births. Am J Epidemiol 2011;173:797-803.

28. Oberg S, Cnattingius S, Sandin S, et al. Birth weight predicts risk of cardiovascular disease within dizygotic but not monozygotic twin pairs: a large population-based co-twin-control study. Circulation 2011;123:2792-8.

29. Marsál K, Persson PH, Larsen T, et al. Intrauterine growth curves based on ultrasonically estimated foetal weights. Acta Paediatrica 1996;85:843-8.

30. Ludvigsson JF, Andersson E, Ekbom A, et al. External review and validation of the Swedish national inpatient register. Bio Med Central Public Health 2011;11:450.

31. Hammar N, Alfredsson L, Rosen M, et al. A national record linkage to study acute myocardial infarction incidence and case fatality in Sweden. Int J Epidemiol 2001;30:S30-4.

32. Lindblad U, Råstam L, Ranstam J, et al. Validity of register data on acute myocardial infarction and acute stroke: the Skaraborg Hypertension Project. Scand J Soc Med 1993;21:3-9.

33. Crump C, Sundquist K, Sundquist J, et al. Gestational age at birth and mortality in young adulthood. JAMA 2011;306:1233-40.

34. Zöller B, Li X, Sundquist J, et al. Gestational age and risk of venous thromboembolism from birth through young adulthood. Pediatrics 2014;134:e473-80.

35. Kazemi T, Sharifzadeh GR, Zarban A, et al. Risk factors for premature myocardial infarction: a matched case-control study. $J$ Res Health Sci 2011;11:77-82.

36. Koupil I, Leon DA, Lithell HO. Length of gestation is associated with mortality from cerebrovascular disease. J Epidemiol Community Health 2005;59:473-4.

37. Zöller B. Low degree of shared genetic susceptibility to coronary artery disease and venous thromboembolism. Thromb Res 2014:134:219-20.

38. Martin $\mathrm{H}, \mathrm{Hu} \mathrm{J}$, Gennser $\mathrm{G}$, et al. Impaired endothelial function and increased carotid stiffness in 9-year-old children with low birthweight. Circulation 2000;102:2739-44.

39. Welberg LA, Seckl JR. Prenatal stress, glucocorticoids and the programming of the brain. $J$ Neuroendocrinol 2001;13:113-28.

40. Armitage JA, Khan IY, Taylor PD, et al. Developmental programming of the metabolic syndrome by maternal nutritional imbalance: how strong is the evidence from experimental models in mammals? J Physiol 2004;561:355-77.

41. Himmelmann A, Svensson A, Hansson L. Relation of maternal blood pressure during pregnancy to birth weight and blood pressure in children. The Hypertension in Pregnancy Offspring Study. J Intern Med 1994;235:347-52.

42. Suter MA, Anders AM, Aagaard KM. Maternal smoking as a model for environmental epigenetic changes affecting birthweight and fetal programming. Mol Hum Reprod 2013;19:1-6.

43. Wren C. Prematurity, low birth weight, and cardiovascular malformations. Pediatrics 2011;127:385-6. 